\author{
R. M. F. Berger \\ M. Y. Berger \\ H. A. van Steensel-Moll \\ G. Dzoljic-Danilovic \\ G. Derksen-Lubsen
}

\section{A predictive model to estimate the risk of serious bacterial infections in febrile infants}

Received: 4 May 1995

Accepted: 20 October 1995

R. M. F. Berger (ه)

H. A. van Steensel-Moll

G. Derksen-Lubsen

Department of Paediatrics,

Sophia Children's Hospital,

Dr Molewaterplein 60,

3015 GJ Rotterdam, The Netherlands

Tel.: 31-104636264

Fax: 31-104636805

\section{Y. Berger}

Centre for Clinical Decision Making,

Erasmus University

Rotterdam, The Netherlands

G. Dzoljic-Danilovic

Department of Microbiology,

University Hospital Rotterdam,

The Netherlands

\begin{abstract}
Low risk criteria have been defined to identify febrile infants unlikely to have serious bacterial infection (SBI). Using these criteria approximately $40 \%$ of all febrile infants can be defined as being at low risk. Of the remaining infants $(60 \%)$ only $10 \%-20 \%$ have an SBI. No adequate criteria exist to identify these infants. All infants aged 2 weeks-1 year, presenting during a 1-year-period with rectal temperature $\geq 38.0^{\circ} \mathrm{C}$ to the Sophia Children's Hospital were included in a prospective study. Infants with a history of prematurity, perinatal complications, known underlying disease, antibiotic treatment or vaccination during the preceding $48 \mathrm{~h}$ were excluded. Clinical and laboratory variables at presentation were evaluated by a multivariate logistic regression model using SBI as the dependent variable. By using likelihood ratios a predictive model was derived, providing a post test probability of SBI for every individual patient. Of the 138 infants included in the study, 33 (24\%) had SBI. Logistic regression analysis defined C-reactive protein (CRP), dura-
\end{abstract}

tion of fever, a standardized clinical impression score, a history of diarrhoea and focal signs of infection as independent predictors of SBI.

\section{Conclusion CRP, duration of} fever, the "standardized clinieal impression score", a history of diarthoea and focal signs of infection were the independent, most powerful predictors of SBI in febrile infants, identified by logistic regression analysis. Although the predictive model is not validated for direct clinical use, it illustrates the clinical potential of the used technique. This technique offers the advantage to assess the probability of SBI in every individual infant. This probability will form the best basis for well-founded decisions in the management of the individual febrile infant.

Key words Infant $\cdot$ Fever $\cdot$ Bacterial infection $\cdot$ Logistic regression
Abbreviations CRP C-reactive protein $\cdot S B I$ serious bacterial infection $\cdot U T I$ urinary tract infection

\section{Introduction}

The evaluation and management of febrile infants remains controversial $[1,3-5,9,14,15,22]$. Serious bacterial infections (SBI) are reported to occur in $3 \%-15 \%$ of these patients and can be difficult to identify $[15,19,23]$. Using the Rochester criteria, or modifications thereof, about $40 \%$ of all febrile infants can be assigned to a low risk group for SBI $[3-5,7-9,14]$. The negative predictive value of these criteria is high (94.6\%-98.9\%) [19]. However, of the remaining $60 \%$ only about $12 \%$ will actually have SBI. The rest is at risk for overtreatment $[1,3,10$, $14,19]$. It thus appears desirable to have positive criteria 
identifying infants at high risk of having SBI. In this study we determined independent predictors of SBI in febrile infants using multivariate logistic regression analysis [17].

\section{Patients and methods}

\section{Patients}

The Sophia Children's Hospital, University Hospital Rotterdam, in the Netherlands has a catchment area of nearly 2 million habitants. The paediatric emergency ward is open $24 \mathrm{~h}$ per day, and admits yearly about 4000 children. These children are either self-referred or referred by a general practitioner. In this study all infants aged 2 weeks-1 year, who presented during a 1-year-period with rectal temperature $\geq 38.0^{\circ} \mathrm{C}$, measured on the ward were prospectively followed. Infants who were born preterm (gestational age $<37$ weeks), had perinatal complications, received antibiotics or had been vaccinated in the $48 \mathrm{~h}$ preceding the visit, and infants with a known previous or underlying disease were excluded. Informed consent was obtained from the parents of the infants.

\section{Variables}

Data on history, observation and physical examination were obtained using a standard form. Clinical impression was standardized using a modification of variables proposed by McCarthy et al. [20, 21]: the child's looking around the room, spontaneous movement of arms and legs, reaching for objects, tonus and hydration. These variables were scored on an ordinal scale $(0=$ normal, $1=$ moderately impaired, 2 = severely impaired). Skin colour was scored as "normal" or "impaired" (i.e. cyanotic, flushed/mottled or pale). The variables which appeared to be significantly associated with SBI in this population were then used to compose a "standardized clinical impression score". Respiratory rales, signs of nucheal rigidity, of enteritis, of arthritis, a skin lesion or a positive urinalysis (as defined below) were considered as "focal signs of infection".

Laboratory data included WBC and differential counts, ESR, Creactive protein (CRP) and urinalysis. Urine was cultured, when the urinalysis was positive, which means a dipstick for leucocyte-esterase was positive and/or ten leucocytes or more per high power field were present in the urinary sediment. Blood samples, nose and throat swabs, and stool specimens were cultured. Lumbar puncture and chest radiography were left to the discretion of the house officer, and tympanocenthesis was performed if suggested by the ENT consultant. Joint fluid and skin were cultured when arthritis or skin lesion respectively, were suspected. All infants were re-evaluated 14 days after presentation. The outcome variable was SBI, defined as bacterial growth in cultures from blood, CSF or urine, or as growth of Salmonella, Shigella or Campylobacter species in stool. Urinary tract infection (UTD) was defined by a urine culture with $\geq 10^{5}$ colonies $/ \mathrm{ml}$ of a single organism. Presumptive clinical diagnosis of otitis media, cellulitis, arthritis and osteomyelitis was regarded as SBI only in combination with bacterial growth in specimen culture from middle ear aspirate, soft tissue, joint and bone respectively. Infants with a chest roentgenogram yielding pulmonary infiltrate, confirmed by an attending radiologist, were considered as having serious illness and included in the SBI group. Staphylococcus epidermidis and other skin commensales were considered to be contaminants in this population of previous healthy infants. Those who defined the outcome were blinded for the predictive findings.

\section{Analysis}

The results were compiled by a predesignated format, and subjected to univariate and multivariate analyses. For univariate analysis, continuous variables were divided into thirds, and the first was used as reference. For the WBC counts the reference was the range between $5,000-15,000 / \mathrm{mm}^{3}$. For variables scored on the three-point ordinal scale, the first category was used as a reference. The $95 \%$ confidence intervals for the risk ratios were calculated according to Woolf [11]. The variables introduced in the logistic regression model were those with perceived clinical relevance, those identified by the univariate analysis, or those reported as of diagnostic value by others. Diagnostic variables were selected on the basis of the maximum likelihood ratio. Variables were included in the model if they substantially improved the log likelihood $(P<0.10)$. The SAS package was used for statistical computations. To calculate post test probabilities and likelihood ratios the mathcad mathematical package was used. In the group of infants without focal signs of infection pretest probability of SBI was estimated based on recent literature data $[3,5,6,14]$.

\section{Results}

Of 196 febrile infants presented to the ward in the study period, 58 (29.6\%) were excluded: 23 for previous antibiotic treatment, 14 for premature birth or perinatal complications, 7 for previous vaccination and 8 for known underlying disease. Six infants were excluded because no blood culture results were available.

A total of 138 infants were enrolled in the study of whom 77 (56\%) were males; 67 (49\%) were referred by a general practitioner, while the remainder were self-referred. Physical examination revealed in 73 infants (53\%) either no cause for the fever or only trivial symptoms of upper respiratory tract infections. SBI was diagnosed in 33 infants (24\%): UTI 9 (2 accompanied by bacteraemia), meningitis 6 (4 with bacteraemia), enteritis 6 (no bacteraemia), pneumonia 5 (no bacteraemia), arthritis/cellulitis 2 (1 with bacteraemia), purulent otitis media 2 (no bacteraemia) and bacteraemia without focal signs of infection 3 . The most frequent SBI was bacteraemia $(n=10,7.3 \%)$. Of the referred and self-referred infants, $31 \%$ and $17 \%$ respectively had SBI (relative risk 1.86, 95\% confidence interval 0.99-3.47).

Univariate analysis revealed that the following variables were associated with a significantly increased risk of SBI: age $<1$ month, duration of fever $\geq 48 \mathrm{~h}$, a history of diarrhoea, focal signs of infection, WBC $>15,000 / \mathrm{mm}^{3}$, more than $3 \%$ band forms in the peripheral smear (or more than 500 band forms $/ \mathrm{mm}^{3}$ ), ESR $>20 \mathrm{~mm} / \mathrm{h}$ and CRP $>20 \mathrm{mg} / \mathrm{l}$. Gender, degree of fever, tonus and hydration were not associated with increased risk ratios (Table 1). Of the variables used to standardize clinical impression, highest scores for "looking around the room", "spontaneously moving arms and legs", and "reaching for objects", as well as an impaired skin colour were associated with statistically significant risk ratios. The sum of these scores was used as a "clinical impression score". An infant, classified by this score as severely ill, had a significant higher statistical risk of SBI (Table 2).

Logistic regression analysis identified CRP, duration of temperature $\geq 38.0^{\circ} \mathrm{C}$, the "clinical impression score", a history of diarrhoea and focal signs of infection as predictors of SBI with the highest discriminating power (values 
Table 1 Univariate analysis of the clinical and laboratory variables. ( $R R$ relative risk, $C I$ $95 \%$ confidence interval)

\begin{tabular}{|c|c|c|c|c|}
\hline Variable & Category & SBI/total & RR & $95 \% \mathrm{CI}$ \\
\hline Gender & $\begin{array}{l}\text { Female } \\
\text { Male }\end{array}$ & $\begin{array}{l}12 / 61 \\
21 / 77\end{array}$ & $\begin{array}{l}1 \\
1.39\end{array}$ & $0.74-2.59$ \\
\hline Age (months) & $\begin{array}{l}-1 \\
-\quad 3 \\
-6 \\
-12\end{array}$ & $\begin{array}{r}5 / 6 \\
7 / 24 \\
8 / 47 \\
13 / 61\end{array}$ & $\begin{array}{l}1 \\
0.35 \\
0.20 \\
0.26\end{array}$ & $\begin{array}{l}0.17-0.72 \\
0.10-0.41 \\
0.14-0.47\end{array}$ \\
\hline $\begin{array}{l}\text { Duration of } \\
\quad \text { temperature }>38^{\circ} \mathrm{C}(\mathrm{h})\end{array}$ & $\begin{array}{l}-24 \\
-48 \\
>48\end{array}$ & $\begin{array}{r}15 / 80 \\
5 / 26 \\
13 / 32\end{array}$ & $\begin{array}{l}1 \\
1.03 \\
2.17\end{array}$ & $\begin{array}{l}0.42-2.56 \\
1.17-4.03\end{array}$ \\
\hline Diarrhoea & $\begin{array}{l}\text { No } \\
\text { Yes }\end{array}$ & $\begin{array}{l}18 / 102 \\
15 / 36\end{array}$ & $\begin{array}{l}1 \\
2.36\end{array}$ & $1.34-4.18$ \\
\hline Temperature $\left({ }^{\circ} \mathrm{C}\right)$ & $\begin{array}{l}38- \\
39- \\
40-\end{array}$ & $\begin{array}{r}13 / 52 \\
16 / 60 \\
4 / 26\end{array}$ & $\begin{array}{l}1 \\
1.07 \\
0.53\end{array}$ & $\begin{array}{l}0.57-2.01 \\
0.28-1.00\end{array}$ \\
\hline $\mathrm{WBC}\left(10^{3} / \mathrm{mm}^{3}\right)$ & $\begin{array}{l}-5 \\
-15 \\
>15\end{array}$ & $\begin{array}{c}1 / 5 \\
15 / 83 \\
17 / 49\end{array}$ & $\begin{array}{l}1.11 \\
1 \\
1.92\end{array}$ & $\begin{array}{l}0.18-6.80 \\
1.06-3.49\end{array}$ \\
\hline $\begin{array}{l}\text { Absolute Bands } \\
\left(10^{3} / \mathrm{mm}^{3}\right)\end{array}$ & $\begin{array}{l}-0.5 \\
-5 \\
>5\end{array}$ & $\begin{array}{c}18 / 103 \\
13 / 30 \\
2 / 2\end{array}$ & $\begin{array}{l}1 \\
2.48 \\
5.72\end{array}$ & $\begin{array}{l}1.38-4.46 \\
2.71-12.10\end{array}$ \\
\hline $\operatorname{ESR}(\mathrm{mm} / \mathrm{h})$ & $\begin{array}{l}-20 \\
-50 \\
>50\end{array}$ & $\begin{array}{r}7 / 70 \\
13 / 36 \\
10 / 15\end{array}$ & $\begin{array}{l}1 \\
3.61 \\
6.67\end{array}$ & $\begin{array}{l}1.58-8.25 \\
3.03-14.68\end{array}$ \\
\hline CRP (mg/l) & $\begin{array}{l}-5 \\
-20 \\
>20\end{array}$ & $\begin{array}{r}1 / 16 \\
4 / 54 \\
25 / 57\end{array}$ & $\begin{array}{l}1 \\
1.19 \\
7.02\end{array}$ & $\begin{array}{l}0.14-9.91 \\
1.03-47.90\end{array}$ \\
\hline
\end{tabular}

Table 2 Univariate analysis of the variables used to standardize clinical impression. The clinical impression score is the sum of the shown observational variables

\begin{tabular}{|c|c|c|c|c|c|}
\hline Variable & Category & Score & SBI/total & $R R$ & $95 \% \mathrm{CI}$ \\
\hline \multirow[t]{5}{*}{ Looking around the room } & Normal & 0 & $16 / 79$ & 1 & \\
\hline & Moderately & & & & \\
\hline & Impaired & 1 & $7 / 39$ & 0.89 & $0.40-1.98$ \\
\hline & Severely & & & & \\
\hline & Impaired & 2 & $10 / 18$ & 2.74 & $0.82-5.00$ \\
\hline \multirow[t]{4}{*}{$\begin{array}{l}\text { Moving arms and legs } \\
\text { spontaneously }\end{array}$} & $\begin{array}{l}\text { Normal } \\
\text { Moderately }\end{array}$ & 0 & $16 / 92$ & 1 & \\
\hline & Impaired & 1 & $9 / 32$ & 1.34 & $0.66-2.72$ \\
\hline & Severely & & & & \\
\hline & Impaired & 2 & $8 / 12$ & 3.83 & $2.11-6.98$ \\
\hline \multirow[t]{5}{*}{ Reaching for objects } & Normal & 0 & $16 / 85$ & 1 & \\
\hline & Moderately & & & & \\
\hline & Impaired & 1 & $5 / 29$ & 0.92 & $0.37-2.28$ \\
\hline & Severely & & & & \\
\hline & Impaired & 2 & $10 / 20$ & 2.66 & $1.43-4.95$ \\
\hline \multirow{2}{*}{$\begin{array}{l}\text { Colour (cyanotic or pale } \\
\text { or flushed/mottled) }\end{array}$} & Normal & 0 & $12 / 75$ & 1 & \\
\hline & Impaired & 2 & $21 / 63$ & 2.08 & $1.12-3.89$ \\
\hline \multirow[t]{4}{*}{ Clinical impression } & Normal & $0-2$ & $12 / 83$ & 1 & \\
\hline & Moderately & & & & \\
\hline & III & $3-5$ & $8 / 30$ & 1.84 & $0.84-4.07$ \\
\hline & Severely ill & $6-8$ & $11 / 21$ & 3.62 & $1.87-7.03$ \\
\hline
\end{tabular}


for one of the variables were missing in 24 infants). None of the infants without focal signs of infection $(n=53)$ appeared to have SBI. For infants with focal signs of infection (values for one of the variables were missing in 18 infants) the highest discriminating power was reached by the same variables found in the total group: CRP, duration of temperature $\geq 38^{\circ} \mathrm{C}$, the clinical impression score and a history of diarrhoea (Table 3 ). For these infants, post test

Table 3 The independent predictors of SBI selected in the logistic regression analysis. (OR odds ratio, $C I 95 \%$ confidence interval of the odds ratio.) The odds ratio is a measure of the increase in risk for SBI. In the variable CRP it represents the risk increase with each $\mathrm{mg} / \mathrm{l}$, in the variable impression score it represents the risk increase with each score point

\begin{tabular}{llll}
\hline Variable & $\begin{array}{l}\text { Coefficient } \\
(n=67)^{\mathrm{a}}\end{array}$ & OR & $95 \% \mathrm{CI}$ \\
\hline CRP $(\mathrm{mg} / \mathrm{ml})$ & 0.03 & 1.03 & $1.01-1.05$ \\
Duration of temp $>48 \mathrm{~h}$ & 1.35 & 3.85 & $1.11-13.34$ \\
Clinical impression $(0-8)$ & 0.20 & 1.22 & $0.95-1.57$ \\
A history of diarrhoea & 1.15 & 3.15 & $0.97-10.19$ \\
\hline
\end{tabular}

a Infants with focal signs of infection

Table 4 Post test probabilities of SBI, given various values of the variables retained in the diagnostic model. A For infants with focal signs of infection. B for infants without focal signs of infection, probabilities of SBI were calculated for the various values of the variables retained in the diagnostic model (Table 4a). The adequacy of fit of the model was as follows: in 16 patients with a predicted probability of SBI $\left(P_{S B I}\right)$ $\leq 0.15$, according to the model 1.7 infants were predicted to have SBI, whereas 1 was observed. In 18 patients $(0.15<$ $\left.P_{S B I} \leq 0.35\right) 4.6$ patients with SBI were predicted, whereas 5 were observed. In 13 patients $\left(0.35<P_{S B I} \leq 0.55\right) 6.4$ infants with SBI were predicted, whereas 8 were observed. Finally, in 20 patients with $P_{S B I}>0.5516 .3$ infants were predicted to have SBI, whereas 15 were observed. $\left(\chi^{2}=\right.$ 0.83 ; degrees of freedom $=2, P>0.1$ ). For infants without focal signs of infection the probability of SBI was 0 . In this group of 53 infants CRP was low (median 11.5 $\mathrm{mg} / \mathrm{l}$, range $3-120 \mathrm{mg} / 1$ ), only 9 infants had been febrile longer than 48 h, 4 scored severely ill, and 8 had a positive history of diarrhoea. For this specific group we assumed a pretest probability of SBI of 0.08 , based on data on prevalence of SBI in comparable infants reported in literature $[3,5,6,14]$. Using the likelihood ratios of the remaining independent predictors of SBI retained in our diagnostic model, we calculated post test probabilities (Table $4 \mathrm{~b})$. According to these calculations, six (11.3\%) of the infants without focal signs of infection would have

based on a pretest probability of 0.08 (see text). Note that the predictive model is not validated for direct clinical use, but is meant as an illustration of the clinical potential of the used technique

A

\begin{tabular}{|c|c|c|c|c|c|c|c|c|c|c|c|c|c|}
\hline \multirow{3}{*}{\multicolumn{2}{|c|}{$\begin{array}{l}\text { Clinical impression } \\
\text { Hours of temp. }>38^{\circ} \mathrm{C} \\
\text { Diarrhoea }\end{array}$}} & \multicolumn{4}{|c|}{ Score $0-2$} & \multicolumn{4}{|c|}{ Score 3-5 } & \multicolumn{4}{|c|}{ Score $6-8$} \\
\hline & & \multicolumn{2}{|l|}{$\leq 48$} & \multicolumn{2}{|l|}{$>48$} & \multicolumn{2}{|l|}{$\leq 48$} & \multicolumn{2}{|l|}{$>48$} & \multicolumn{2}{|l|}{$\leq 48$} & \multicolumn{2}{|c|}{$>48$} \\
\hline & & No & Yes & No & Yes & No & Yes & No & Yes & No & Yes & No & Yes \\
\hline \multirow[t]{7}{*}{ CRP mg/1 } & 5 & 0.05 & 0.16 & 0.15 & 0.40 & 0.10 & 0.29 & 0.28 & 0.59 & 0.20 & 0.47 & 0.47 & 0.76 \\
\hline & 25 & 0.08 & 0.25 & 0.25 & 0.55 & 0.17 & 0.43 & 0.42 & 0.73 & 0.31 & 0.62 & 0.61 & 0.85 \\
\hline & 45 & 0.14 & 0.38 & 0.37 & 0.67 & 0.27 & 0.57 & 0.57 & 0.83 & 0.45 & 0.75 & 0.74 & 0.91 \\
\hline & 65 & 0.23 & 0.53 & 0.52 & 0.80 & 0.40 & 0.71 & 0.71 & 0.90 & 0.60 & 0.84 & 0.84 & 0.95 \\
\hline & 85 & 0.36 & 0.67 & 0.66 & 0.88 & 0.55 & 0.82 & 0.81 & 0.94 & 0.72 & 0.91 & 0.91 & 0.97 \\
\hline & 105 & 0.50 & 0.79 & 0.78 & 0.93 & 0.69 & 0.89 & 0.89 & 0.97 & 0.83 & 0.95 & 0.95 & 0.99 \\
\hline & 155 & 0.82 & 0.94 & 0.94 & 0.98 & 0.91 & 0.97 & 0.97 & 0.99 & 0.96 & 0.99 & 0.99 & 1 \\
\hline
\end{tabular}

B

\begin{tabular}{|c|c|c|c|c|c|c|c|c|c|c|c|c|c|}
\hline \multirow{3}{*}{\multicolumn{2}{|c|}{$\begin{array}{l}\text { Clinical impression } \\
\text { Hours of temp. }>38^{\circ} \mathrm{C} \\
\text { Diarrhoea }\end{array}$}} & \multicolumn{4}{|c|}{ Score $0-2$} & \multicolumn{4}{|c|}{ Score 3-5 } & \multicolumn{4}{|c|}{ Score $6-8$} \\
\hline & & \multicolumn{2}{|l|}{$\leq 48$} & \multicolumn{2}{|l|}{$>48$} & \multicolumn{2}{|l|}{$\leq 48$} & \multicolumn{2}{|l|}{$>48$} & \multicolumn{2}{|l|}{$\leq 48$} & \multicolumn{2}{|c|}{$>48$} \\
\hline & & No & Yes & No & Yes & No & Yes & No & Yes & No & Yes & No & Yes \\
\hline \multirow[t]{7}{*}{ CRP mg/1 } & 5 & 0.006 & 0.02 & 0.02 & 0.07 & 0.01 & 0.04 & 0.04 & 0.14 & 0.03 & 0.09 & 0.09 & 0.26 \\
\hline & 25 & 0.01 & 0.04 & 0.04 & 0.12 & 0.02 & 0.08 & 0.07 & 0.23 & 0.05 & 0.15 & 0.15 & 0.39 \\
\hline & 45 & 0.02 & 0.06 & 0.06 & 0.20 & 0.04 & 0.13 & 0.13 & 0.35 & 0.08 & 0.25 & 0.24 & 0.54 \\
\hline & 65 & 0.03 & 0.11 & 0.11 & 0.31 & 0.07 & 0.21 & 0.21 & 0.49 & 0.14 & 0.38 & 0.37 & 0.68 \\
\hline & 85 & 0.06 & 0.18 & 0.18 & 0.45 & 0.12 & 0.33 & 0.33 & 0.64 & 0.23 & 0.52 & 0.52 & 0.80 \\
\hline & 105 & 0.10 & 0.29 & 0.29 & 0.59 & 0.20 & 0.48 & 0.47 & 0.76 & 0.35 & 0.67 & 0.66 & 0.88 \\
\hline & 155 & 0.33 & 0.65 & 0.64 & 0.87 & 0.52 & 0.80 & 0.80 & 0.94 & 0.71 & 0.90 & 0.90 & 0.97 \\
\hline
\end{tabular}


been thought to have an increased post test probability of SBI $(P>0.08)$, ranging from $0.10-0.61$. The other infants all had decreased post test probabilities ranging from $0.006-0.04$.

\section{Discussion}

Age, temperature, toxic appearance and the modified Rochester criteria have been proposed as important diagnostic features in the management of febrile infants and children [4].

In this study we looked for independent clinical and laboratory criteria for the diagnosis of SBI in febrile infants using multivariate analysis. We found that CRP, the duration of fever, a "standardized clinical impression score", a history of diarrhoea and focal signs of infection were the variables with the strongest discriminating power for SBI. Although the variables age, WBC and the band count were, using univariate analysis, associated with an increased risk of SBI, they provided no additional value in discriminating those febrile infants with or without SBI.

The prevalence of SBI in our study $(24 \%)$ was high in comparison to other reports $[3,4,14]$. This may be attributed to the high percentage of infants (49\%) referred by general practioners since the prevalence of SBI in the referred infants was almost double that in the self-referred infants. In our study $83 \%$ of infants less than 28 days of age were diagnosed as SBI. This high prevalence is in concordance with previous reports and supports the recently published guidelines that these infants be admitted to hospital and started on antibiotic treatment pending culture results $[4,19]$. In contrast to other reports the risk for SBI in infants $1-3$ months was no greater than the risk in infants aged 3-12 months $[4,6,23]$.

The clinical impression is a key component in various studies on febrile infants $[2,8,14,21]$. The description "toxic appearance" is however subjective and dependent on the physicians experience $[19,23]$. We therefore devised a "standardized score of clinical impression" based on objective observations applicable to infants in this age group. These observations are simple to perform and less dependent on the physicians experience $[20,21]$.

The logistic regression function used in this study offers distinct advantages. By defining cut off points at which a test is positive or negative, information on the total range of values of a variable is lost. Using the logistic regression function the complete information provided by a continuous variable can be maximally used. In addition dependencies between the results of different tests can be taken into account. Given these properties more precise estimates of the post test probability of SBI can be calculated. The coefficients in the regression model (Table 3), illustrating the potential of each variable in discriminating between SBI and no SBI, are valid in every population. After adjusting the pretest probability, which is determined by the prevalence of SBI in a specific population, the model can be used in various populations. Using this predictive model post test probabilities for every febrile infant aged 2 weeks to 1 year, can be calculated. The value of this kind of model is in guiding threshold based decision making [26]. The decision to withhold therapy depends on the no treatment threshold, which is a measure of the balance of the benefits of the treatment of infants with SBI and the costs and risks of treatment of infants without SBI. The management of infants with suspected SBI should take into account the costs to the individual infant in terms of hospitalization and side-effects of antibiotic treatment but also the costs to the community, as unnecessary antibiotic treatment may increase resistance to antibiotics. Formal decision analysis may help to find the probability of SBI at which the trade off between the costs and benefits of treatment is most favourable for the patient, paediatrician and community $[16,22]$.

It has been stated that febrile infants who present with focal signs of infection do not pose diagnostic or theraupeutic dilemmas $[4,25]$. Our results contradict these statements as the prevalence of SBI in febrile infants with a focal sign of infection was $44 \%$. Had all febrile infants with a focal sign of infection been treated for SBI, more than half would have been treated unnecessarily, incurring needless risks and expenses $[10,16]$. The probability of SBI in a patient with a focal sign of infection can be estimated more precisely by our defined independent predictors. For example, by applying our diagnostic model to an infant with a focal sign of infection, a clinical impression score $0-2$, no history of diarrhoea, a temperature of less than $48 \mathrm{~h}$ duration and a CRP of $5 \mathrm{mg} / \mathrm{l}$, one can reduce the probability of SBI from 0.44 to 0.05 . Had the CRP been $155 \mathrm{mg} / \mathrm{l}$ our diagnostic model would adjust the risk for SBI in this infant to 0.82 .

Certain aspects of our study require further explanation. In the group of infants without focal signs of infection no patients had SBI, thus presuming a negative predictive value of $100 \%$. This result may be due to the small number of patients in our study. Based on comparability with other studies we assumed a pretest probability of $8 \%$ in this group of infants $[3,5,6,14]$. The high prevalence of SBI in the total group might be influenced by the high proportion of patients referred by a general practioner. In our study no SBI not identified by work up at presentation was detected during the 14-day follow up. A lumbar puncture and urine culture were not routinely performed in all infants. Because of the 14-day follow up period we feel that missed bacterial menigitis could be excluded. Urine samples were only cultured when the urine screening was positive. Although the negative predictive value of a screening method using combined elements of urinanalysis has been demonstrated to be high, UTI's might have been missed $[7,13,18,24]$. However the prevalence 
of UTI in our population (7\%) and the percentage of UTI in relation to the total number of SBI $(27 \%)$ is comparable to the percentages reported in the literature [3, 4, 12]. These results plus the negative findings after a 14-day follow up period make it unlikely that any UTT's were missed.

We conclude that the independent predictors of SBI in febrile infants, identified using logistic regression analysis, were CRP, the duration of fever, a "standardized clinical impression score", a history of diarrhoea and focal signs of infection. However, our diagnostic model must still be prospectively validated in other population groups. The purpose of its presentation is therefore not to advocate its immediate use in practice but to illustrate its clinical potential in the management of febrile infants. This approach offers the advantage of assessing the probability of SBI in individual infants, providing the best basis for well-founded decisions in the management of these infants.

\section{References}

1. Avner JR, Crain EF, Baker MD (1993) Failure to validate the Rochester criteria for evaluation of febrile infants. Am J Dis Child 147: 441

2. Baker MD, Avner JR, Bell LM (1988) Failure of infant observation scales to identify serious illness in febrile 1 - to 2-month- old infants. Am J Dis Child 142: 390

3. Baker MD, Bell LM, Avner JR (1993) Outpatient management without antibiotics of fever in selected infants. N Engl J Med 329: 1437-1441

4. Baraff LJ, Bass JW, Fleisher GR, Klein JO, McCracken GH, POwell KR, Schriger DL (1993) Practice guideline for the management of infants and children 0 to 36 month of age with fever without a source. Pediatrics $92: 1-12$

5. Baskin MN, O'Rourke EJ, Fleisher GR (1992) Outpatient treatment of febrile infants 28 to 89 days of age with intramuscular administration of ceftriaxone. J Pediatr 120: 22-27

6. Bonadio WA (1990) Evaluation and management of serious bacterial infections in the febrile young infant. Pediatr Infect Dis J 9: 905-912

7. Chernow B, Zaloga GP, Soldano S, et al (1984) Measurement of urinary leucocyte esterase activity: a screening test for urinary tract infections. Ann Emerg Med 13: 150-154

8. Dagan R, Powell KR, Hall CB, Menegus MA (1985) Identification of infants unlikely to have serious bacterial infection although hospitalized for suspected sepsis. J Pediatr 107: 855-860
9. Dagan R, Sofer S, Phillip M, Shachak E (1988) Ambulatory care of febrile infants younger than 2 months of age classified as being at low risk for having serious bacterial infections. J Pediatr 112: 355-360

10. De Angelis C, Joffe A, Wilson M, et al (1983) Iatrogenic risks and financial costs of hospitalizing febrile infants. Am J Dis Child 137: 1146-1149

11. Gardner MJ, Altman DG (1989) Statistics with confidence. BMJ 50-63

12. Hoberman A, Chao HP, Keller DM, Hickey R, Davis HW, Ellis D (1993) Prevalence of urinary tract infection in febrile infants. J Pediatr 123: 17-23

13. Hoberman A, Wald ER, Reynolds EA, Penchanski L, Charron M (1994) Pyuria and bacteriuria in urine specimens obtained by catheter from young children with fever. J Pediatr 124: $513-519$

14. Jaskiewicz JA, McCarthy CA, Richardson AC, White KC, Fisher DJ, Dagan R, Powell KR (1994) Febrile infants at low risk for serious bacterial infection - an appraisal of the Rochester criteria and implications for management. $\mathrm{Pe}$ diatrics 94: 390-396

15. Klein JO, Schlesinger PC, Karasic RB (1984) Management of the febrile infant three months of age or younger. Pediatr Inf Dis J 3: 75-79

16. Lieu TA, Schwartz JS, Jaffe DM, Fleisher GR (1991) Strategies for diagnosis and treatment of children at risk for occult bacteremia: clinical effectiveness and cost-effectiveness. J Pediatr 118: $21-29$
17. Linnet K (1988) A review on the. methodology for assessing diagnostic tests. Clin Chem 34: 1379-1386

18. Lohr JA, Portilla MG, Geuder TG, Dunn ML, Dudley SM (1993) Making a presumptive diagnosis of urinary tract infection by using a urinalysis performed in an on-site laboratory. J Pediatr 122: 22-25

19. McCarthy PL (1994) The febrile infant. Pediatrics 94: 397-398

20. McCarthy PL, Jekel JF, Stashwick CA, et al (1981) Further definition of history and observation variables in assessing febrile children. Pediatrics 67 : 687-693

21. McCarthy PL, Sharpe MR, Spiesel SZ, et al (1982) Observation scales to identify serious illness in febrile children. Pediatrics 70: 802-809

22. Pantell RH, Berwick DM (1990) Costeffectiveness analysis in pediatric practice. Pediatrics 85: 361-363

23. Powell KR (1990) Evaluation and management of febrile infants younger than 60 days of age. Pediatr Infect Dis J 9: 153-157

24. Sawyer P, Stone LL (1984) Evaluation of a leucocyte dip-stick test used for screening urine cultures. J Clin Microbiol 20: $820-821$

25. Shapiro ED (1986) Bacteremia in the febrile child. Year Book Medical Publishers Inc.

26. Sox HC, Blatt MA, Higgins MC, Marton KI (1988) Medical decision Making. Butterworths, Boston 